\title{
Resenha
}

\section{Direito à saúde: Dilemas do fenômeno da judicialização da saúde}

Review

Rights to health: Dilemmas of the phenomenon of health judicialization

Reseña

Derecho a la salud: Dilemas del fenómeno de la judicialización de la salud

\section{Tarsila Costa do Amaral ${ }^{1}$}

Dilemas do Fenômeno da Judicialização da Saúde é o título do segundo volume da Coletânea de Direito à Saúde, lançada no ano de 2018 pelo Conselho Nacional de Secretários de Saúde (CONASS). A obra Institutucionalização que inaugurou a coletânea apresentou ao leitor o arcabouço normativo que ampara a efetivação do direito à saúde desde a Constituição até as normas político-administrativas que regem o funcionamento do Sistema Único de Saúde (SUS) passando, inclusive, pelo estudo do contexto internacional sobre o tema.

Neste segundo livro, estão reunidos vinte e cinco textos que discutem as convergências e contradições que atravessam a judicialização da saúde, seus limites, dimensões e perspectivas, sob o ponto de vista jurídico, ético, econômico e político.

Os autores são juízes, procuradores jurídicos, gestores do SUS e a acadêmicos cuja atuação profissional se relaciona com o direito à saúde. De maneira geral, os textos deste segundo volume propõem que a judicialização da saúde seja debatida a partir da aproximação dos saberes jurídicos e dos saberes técnicos do campo da saúde coletiva, incluídos os aspectos sociais e econômicos que participam da construção da Política Pública de Saúde.

Interessante notar que a partir dos textos de autoria dos juízes Clenio Jair Schulze (1), Eduardo Perez Oliveira (2) e Leonardo Buísssa, este último em co-autoria com procuradores do estado e do município (3), é possível compreender que o fenômeno da

\footnotetext{
${ }_{1}^{1}$ Advogada; mestra em Saúde Coletiva pela Faculdade de Ciências Médicas da Universidade de Campinas (UNICAMP). Assessora da Prefeitura de Jundiaí, SP. https://orcid.org/0000-0001-5882-3120. E-mail: tarsilacamaral@gmail.com
} 
judicialização da saúde, de fato, é permeado por uma série de dilemas e controvérsias que ao final convergem para conclusões muito similares.

No texto de Schulze (1) ele fala da judicialização do impossível e aponta as dificuldades com as quais se depara o magistrado no julgamento de demandas de saúde. Tais conflitos estão presentes tanto nos casos que envolvem decisões sobre a manutenção da vida, como nos casos em que fica evidente a atuação dos laboratórios farmacêuticos de maneira aética neste cenário. O magistrado critica a questão da precificação dos medicamentos, a transparência na atuação dos laboratórios, a promessa de terapêuticas sem comprovação científica às custas do erário público. Por fim, Schulze conclui que a qualificação do judiciário em relação a estas questões é estratégia fundamental ao avanço das discussões sobre a judicialização da saúde no Brasil e a garantia de qualidade de vida para o indivíduo e para a sociedade.

Oliveira (2), no mesmo sentido, destaca a necessidade de maior controle dos dados da judicialização da saúde, em especial, aqueles que denunciem a associação de médicos, escritórios de advocacia e laboratórios farmacêuticos, como medida fundamental para inibir o uso predatório do judiciário pela busca de tecnologias que não foram consagradas pelas melhores evidências científicas disponíveis, defendendo que as demandas judiciais devem ser julgadas com base em critérios objetivos e pela defesa dos interesses coletivos, sobretudo.

Já Buíssa, Bevilacqua e Moreira (3) atribuem a crescente judicialização da saúde às precariedades do SUS que, segundo os autores, "não se converte numa entrega efetiva de um serviço público de qualidade para a população" (3, p. 27). Defendem que os autores das ações judiciais são aqueles que não obtiveram do Estado a prestação voluntária de cuidados em saúde e ressalva que esta situação tem origem em um progressivo sucateamento do SUS desde sua conformação jurídica a partir da Constituição de 1988. Concluem que é papel do Poder Judiciário atuar na implementação de novas políticas públicas na área de saúde e que limitações orçamentárias não devem ser utilizadas sem que haja prova robusta da impossibilidade financeira do ente público.

A partir das leituras trazidas nesta obra, temos uma clara dimensão de quão controvertido pode ser o tema da judicialização da saúde, eis que conduz a dilemas que perpassam tanto as dificuldades orçamentárias enfrentadas pelos gestores do SUS, como 
pelo do lobby poderoso da indústria farmacêutica sobre a classe médica, jurídica e científica. A judicialização da saúde se agrava pela má gestão do recurso público e pela pouca vontade política em relação ao ajuste de financiamento do Sistema e estas questões são tão dilemáticas quanto as demais. Todos estes fatores corroboram para o aumento de ações judiciais para obtenção de tratamentos de saúde.

Em relação ao enfoque sobre o financiamento do SUS, alguns autores deste segundo volume escreveram sobre as agruras orçamentárias enfrentadas pela União e pelos Estados por conta do número elevado de ações judiciais nas quais àqueles entes são condenados a fornecer tratamentos de saúde. Xavier (4) e Paim (5) trazem dados quantitativos sobre o impacto das ações judiciais na área de saúde no âmbito do orçamento federal e fazem críticas em relação à concessão de ordens judiciais para o fornecimento de medicamentos sem registro na Agência Nacional de Vigilância Sanitária (Anvisa) e não constantes das listas de medicamentos (Rename) e procedimentos (Renases) do SUS.

De outro lado, Castelo (6) defende em seu artigo que a União deve assumir a responsabilidade pelo fornecimento de medicamentos oncológicos, rechaçando a tese da solidariedade dos entes públicos em relação a estes tratamentos. Afirma ainda que a União deve ressarcir os Estados quando responsabilizados por este atendimento por força de ordens judiciais. No mesmo sentido é o argumento trazido por Alves, Oliveira e Strapasson (7) quando elaboram relato detalhado sobre a Judicialização de Medicamentos Oncológicos na Secretaria de Saúde do estado do Paraná. Aliás, ainda no contexto do estado do Paraná, os autores Pontarolli, Rossignoli e Moretoni (8) apresentam artigo que traz estudo descritivo observacional sobre a evolução das demandas judiciais por medicamentos entre os anos de 2013 e 2017 e seu relevante impacto nas finanças públicas e na gestão da saúde daquele estado. Outro ente da federação presente nas discussões desde segundo volume é o estado do Rio Grande do Sul, cujos impactos da judicialização da saúde estão descritos no trabalho de Naundorf, Carli e Goulart (9) e, segundo os autores, interferem diretamente nas rotinas administrativas de gestão de recursos humanos e financeiros da Secretaria de Estado da Saúde.

Ainda no campo de estudo do financiamento do SUS, merece destaque o artigo da Procuradora do Ministério Público de Contas do Estado de São Paulo, Élida Graziane Pinto (10) que discorre sobre o Estado de Coisas Inconstitucional e denuncia uma guerra fiscal 
implícita deflagrada pelo descumprimento sistemático da Constituição de 1988 por parte da União, através da edição de sucessivas emendas constitucionais e omissões que resultaram na indefinição das competências federativas de cada ente político na execução de ações e serviços públicos de saúde. Segundo a autora, esses fatos causaram desarranjos organizacionais e impulsionaram um processo de desfinancimento do SUS, responsável por sua inefetividade. A procuradora defende que a judicialização seja utilizada para combater estes desajustes orçamentários pela revisão de emendas constitucionais pelo judiciário, de modo a que seja possível haver um "rateio federativo dos recursos com o enfoque do art. $198, \S 3^{\circ}$, II (progressiva redução das disparidades regionais)".

Forçoso reconhecer que o SUS perde com a falta de financiamento adequado ao modelo de acesso universal, integral e igualitário a que se propõe e que a judicialização da saúde agrava este cenário. Contudo, a este contexto soma-se um fator preponderante que é a influência dos laboratórios na tomada de decisão dos prescritores, principalmente médicos especialistas, protagonistas nas ações judiciais na área da saúde.

Neto, Gonçalves e Andrade (11) abordam o assunto e identificam estratégias utilizadas pelo poder econômico ligado às indústrias farmacêuticas com o objetivo de pressionar os governos a orientar a implementação de políticas públicas com base nos interesses do Complexo Econômico-industrial da Saúde. Os autores reúnem dados de estudos diversos que demonstram haver uma rede complexa de interações entre médicos, advogados, gestores, promotores de justiça e magistrados no plano das ações judiciais para fornecimento de tratamentos em saúde. Concluem que os argumentos de defesa da vida e da saúde do indivíduo frequentemente confundem-se com a viabilização da aquisição, via recursos públicos, de determinadas drogas e terapias que em certa perspectiva, atenderiam muito mais a interesses de poder econômico do que a terapêutica mais indicada aos pacientes.

Um caso emblemático acerca do uso da judicialização da saúde no Brasil por grandes grupos farmacêuticos é o caso da judicialização do medicamento Soliris ${ }^{\circledR}$ (eculizumabe) que é tema do artigo de Melo, Oliveira, Siqueira e Muller (12). Neste trabalho, os autores comentam a manobra estratégica da fabricante que evitou o registro do medicamento na Anvisa por quase dez anos e a morosidade da gestão do SUS que demorou mais dois anos para estabelecer o preço máximo de venda do medicamento pela Câmara de Regulação do 
Mercado de Medicamentos (CMED), deixando assim de evitar prejuízos de alta monta ao orçamento da saúde.

Outro caso presente nesta obra e que discute o uso do poder econômico das indústrias farmacêuticas em desfavor da coletividade é o caso do estado do Tocantins, relatado no artigo de Calumby (13). O autor denuncia os "Desafios da aquisição de medicamentos pela administração pública fora dos grandes centros populacionais do país e o conflito entre direitos" (2018, p. 121-131) e relata a disputa judicial do estado do Tocantins para o enfrentamento do desabastecimento de medicamentos oncológicos causado pela recusa dos grandes laboratórios em participar das licitações nos processos de compras públicas de hospitais habilitados para o cuidado em oncologia.

Temos então que o financiamento insuficiente do SUS sofre pressões importantes do mercado farmacêutico e a judicialização da saúde é o instrumento pelo qual as indústrias do setor pressionam os governos para a incorporação de novas tecnologias. Nesse contexto, o poder judiciário se torna o ordenador dos recursos do SUS proferindo decisões judiciais sem considerar os Limites à Judicialização da Saúde Pública no Direito Brasileiro, assunto que é tema do artigo de Silva Junior (14), procurador do Estado do Amapá. Silva Junior propõe que a judicialização seja debatida a partir de critérios racionais, concluindo que o sistema judiciário deve garantir a efetividade dos serviços de saúde não somente àqueles que promovem ações judiciais, mas também a quem não tem sequer acesso à justiça. No mesmo sentido, Pereira (15) coloca o seguinte questionamento:

qual é o limite para a intervenção do Poder Judiciário ao desrespeitar o que fora planejado para ser executado através da política pública em saúde, aproximando-se de uma abordagem individualista dos problemas sociais?"(15, p. 109).

O poder judiciário recebe diariamente milhares de ações judiciais cujo tema é o fornecimento de tratamentos de saúde e para cada uma destas demandas existe um processo judicial que tramita por anos no sistema judiciário brasileiro. Ao longo do tempo, as discussões sobre a judicialização da saúde ganharam contornos diversos e o seu caráter controverso também enseja debates jurídicos de natureza processualista. Neste segundo volume da Coletânea de Direito à Saúde, alguns autores como Moliterno (16) e Naves (17) discutem, por exemplo, a eleição da via estreita do mandado de segurança pelos advogados e defensores públicos e a impropriedade de sua utilização irrestrita, respectivamente, 
afirmando que a via processual do mandado de segurança só seria cabível nos casos em que o autor da ação judicial estivesse pleiteando medicamentos ou terapias já disponíveis no SUS pois somente nestes casos haveria direito líquido e certo que autorizaria a concessão da ordem de fornecimento do produto.

Ainda na seara processual, Juliano (18) aborda a questão das condições da ação que devem estar presentes como requisito na propositura de ações judiciais na área da saúde, em especial, a legitimidade das partes (ativa ou passiva) e o interesse de agir. $O$ autor defende que, apesar de todas as pessoas possuírem direito ao acesso à tratamentos de saúde, o direito à saúde engloba "não somente a ausência de doença, mas sim uma vida digna" (2018, p.229) e, para que seja possível requerer ao judiciário estas garantias, necessário se faz eleger corretamente o ente federativo responsável para figurar no polo passivo da ação, bem como, esgotar as vias administrativas para a obtenção destas pretensões. Por fim, Santos (19) traz apontamentos importantes acerca dos prazos exíguos aos quais são submetidos os gestores do SUS no âmbito da judicialização da saúde e analisa os impactos que estas decisões, muitas vezes de cumprimento impossível, geram ao erário público, à organização das contas públicas e aos gestores, em termos de responsabilização por atos de improbidade administrativa, por exemplo. $\mathrm{O}$ autor propõe a criação de núcleos específicos para atendimento de demandas judiciais e aquisição de medicamentos e procedimentos, citando o caso do Estado de Tocantins, de modo a que seja possível para as secretarias de saúde cumprir os prazos imputados pelo judiciário para o fornecimento de tratamentos de saúde individuais.

Ampliando a análise do fenômeno da judicialização da saúde para além dos aspectos jurídicos e a partir dos dilemas que emergem do tema, fundamental comentar os artigos de Sant'Ana (20), defensora pública do Distrito Federal e Araújo (21), advogada da Procuradoria Geral da União em Minas Gerais, que nos convidam a uma reflexão necessária sobre que tipo de direito à saúde o judiciário brasileiro vem garantindo. Araújo (21) questiona: "qual direito à saúde?", lembrando que no âmbito da judicialização da saúde discutimos questões como a "excessiva e desleal influência da indústria farmacêutica, a desatualização do médico, o elevado receio de responsabilização por parte do profissional, a ausência de financiamento adequado de políticas públicas, a presunção estatal" $(2018$, p.292) e alerta para a importância de serem considerados os aspectos humanos sem, contudo, afastar-se 
da racionalidade necessária ao julgamento destes pedidos. Sant'Ana (20), por sua vez, traz à baila o ponto crucial, que é a desigualdade abissal vivenciada pela sociedade brasileira, que não pode estar dissociada da análise do fenômeno da judicialização da saúde. O autor defende o "uso da judicialização da saúde como instrumento político e democrático de afirmação da cidadania das classes populares contra a injustiça ocasionada pelas desigualdades socioeconômicas" e o "papel do acesso à justiça como reação a este contexto" (2018, p.78). O texto nos faz refletir o fenômeno da judicialização da saúde a partir de um "outro lugar", o lugar dos excluídos, aqueles que não tem acesso às condições mínimas de dignidade humana para sua sobrevivência e ensina que "a tarefa do direito, dos juristas e dos gestores da saúde deve ser a promoção de mudanças na sociedade e suas instituições, em prol de mais inclusão e progresso para a saúde da população e que a judicialização da saúde é, sobretudo, reação a um contexto de exclusão" (2018, p.83).

Caminhando para o final desta resenha, importante citar o artigo de Mekanna e Bardaro (22) que critica o uso da judicialização da saúde para a viabilização indiscriminada de internações compulsórias para tratamento de indivíduos com necessidade de cuidados em saúde mental ou em uso problemático de substâncias, na contramão do que prevê a Lei n 10.216/2001 (Lei da Reforma Psiquiátrica). O texto aponta que boa parte das ordens judiciais proferidas para o custeio de vagas de internação pelo poder público sequer estão lastreadas por laudos médicos, contrariando a previsão legal. $O$ artigo também denuncia situações de privação de liberdade e violação de direitos humanos oriundos de decisões que desconsideram as disposições constitucionais e legais sobre o tema e defende que se viabilize maiores investimentos para implantação efetiva da rede comunitária de serviços públicos voltados ao cuidado em saúde mental, álcool e outras drogas.

No campo das garantias de dignidade humana e respeito à autonomia dos indivíduos, a obra sob análise traz as lúcidas reflexões da advogada e doutora em saúde pública Lenir Santos (23), que discorre sobre o direito de morrer e o respeito à autonomia da vontade como necessária adequação ética à tomada de decisões em saúde, em especial, pelo uso do consentimento informado na relação médico-paciente e pela ampliação da discussão sobre a obstinação terapêutica que, segundo a autora, "não leva a nenhum lugar, exceto sofrimento indevido e esforços inúteis, com custos" (2018, p.269) . A autora afirma que "as indústrias farmacêuticas e os fabricantes de tecnologias em saúde visam lucro, 
fundamentalmente, e não o humanismo" (2018, p.273). Finaliza propondo que o processo de morrer seja devidamente regulado, com a criação de parâmetros e protocolos dignos e humanos.

O segundo volume da Coletânea encerra o seu conjunto de artigos com dois textos que reafirmam a judicialização da saúde como um fenômeno dilemático a ser compreendido. Gadelha (24) discorre sobre os impasses entre o direito individual e coletivo e a inaceitação dos limites orçamentários e científicos que permeia os processos judiciais na área da saúde. A autora propõe uma interpretação do direito à saúde que contemple os princípios constitucionais da universalidade e da integralidade associados ao modelo sistêmico de saúde eleito pela Constituição e regulamentado pela Lei Orgânica da Saúde (Lei n ${ }^{\circ}$ 8080/90) e revela que a maior parte do recurso destinado às ações e serviços de saúde no SUS é destinado ao custeio de instituições privadas, seja através de contratos e convênios, seja através de isenções fiscais e também pela judicialização da saúde. Finaliza o artigo denunciando o desequilíbrio causado pela judicialização da saúde, a confusão hegemônica no discurso existente entre saúde e medicalização e a incorporação acrítica de novas tecnologias ao Sistema, causando injustiças no acesso e um absoluto descontrole financeiro e orçamentário.

Finalmente, no último texto deste volume, Vilela, Moliterno e Santos (25) convidam à reflexão sobre os dilemas impostos pela judicialização da saúde e a importância da aproximação entre os sistemas sanitário e de justiça para a promoção de diálogos institucionais e interlocução entre poderes, com vistas ao fortalecimento do SUS e não a sua desconstrução pelo desfinanciamento e desestruturação. $O$ artigo final, portanto, nos convida à leitura do terceiro e último volume da Coletânea de Direito à Saúde: Boas Práticas e Diálogos Institucionais.

\section{Referências}

1. Schulze CJ. Direito à saúde e a judicialização do impossível. In: Santos AO, Lopes LT, organizadores. Coletânea direito à saúde: dilemas do fenômeno da judicialização da saúde. Brasília: CONASS; 2018. p.14-24.

2. Oliveira EP. Um necessário amadurecimento das demandas em saúde. Ibidem. p. 276285. 
3. Buíssa L, Bevilacqua L, Moreira FHBB. Impactos orçamentários da judicialização das políticas públicas de saúde. Ibidem. p. 26-50.

4. Xavier C. Judicialização da saúde: perspectiva crítica sobre os gastos da união para o cumprimento de ordens judiciais. Ibidem. p. 52-61.

5. Paim P. Os passos do SUS: do apogeu à falência. A judicialização da saúde. Ibidem. p. 86-91.

6. Castelo FA. A necessidade de estabelecer a responsabilidade da união nas ações que buscam o fornecimento de medicamentos oncológicos. Ibidem. p. 132-145.

7. Alves SMP, Oliveira FSW, Strapasson GC. A judicialização de medicamentos oncológicos na Secretaria de Estado da Saúde do Paraná: caracterização e dificuldade de gestão. Ibidem. p.146-156.

8. Pontarolli D, Rossignoli P, Moretoni C. Panorama da judicialização de medicamentos na Secretaria de Estado da Saúde do Paraná. Ibidem. p.174-196.

9. Naundorf B, Carli P, Goulart B. O estado do Rio Grande do Sul e os impactos da judicialização da saúde na gestão pública. Ibidem. p. 208-217.

10. Pinto EG. Guerra fiscal de despesas na pactuação federativa do SUS: um ensaio sobre a instabilidade de regime jurídico do piso federal em saúde. Ibidem. p.92-106.

11. Neto OHC, Gonçalves LA de O, Andrade EIG. Estratégias do poder econômico interferindo no fenômeno da judicialização da saúde. Ibidem. p.62-75.

12. Melo DO, Oliveira DB, Siqueira PSF, Muller SS. SOLIRIS® (eculizumabe): vários aspectos da judicialização. Ibidem. p. 158-173.

13. Calumby MS. Desafios na aquisição de medicamentos pela administração pública fora dos grandes centros populacionais do país e o conflito entre direitos fundamentais - livre iniciativa $x$ direito à saúde: caso Tocantins. Ibidem. p. 120-131.

14. Silva Junior RS. Limites à judicialização da saúde pública no direito brasileiro. Ibidem. p. 254-263.

15. Pereira SPD. A efetivação do direito à saúde no contexto da judicialização da política pública. Ibidem. p. 108-118.

16. Moliterno MP. Da imprescindível análise fática nas demandas de saúde: impropriedade da utilização irrestrita do mandado de segurança. Ibidem. p.198-207.

17. Naves AN. A regra da inadequação da via estreita do mandado de segurança em demandas de saúde. Ibidem. p.234-241. 
18. Juliano RAB. As condições da ação nas demandas judiciais envolvendo o direito à saúde. Ibidem. p. 218-233.

19. Santos FM. Decisão judicial com prazo de cumprimento exíguo $x$ responsabilidade administrativa do gestor da área da saúde: análise da problemática advinda da judicialização. Ibidem. p.188-196.

20. Sant'Ana RN. Saúde, desigualdade e judicialização: vamos ou não vamos dar instrumentos para a insurgência dos excluídos? Ibidem. p. 76-85.

21. Araújo CP. Qual direito à saúde? Ibidem. p. 286-294.

22. Mekanna PA, Bardaro R. A internação compulsória na contramão da Lei no 10.216/01. Ibidem. p. 242-252.

23. Santos L. Direito de morrer: uma discussão necessária. Ibidem. p.264-275.

24. Gadelha MIP. A questão judiciária no SUS. Ibidem. p. 296-307.

25. Vilela LM, Moliterno MP, Santos AO. Judicialização da saúde: um fenômeno a ser compreendido. Ibidem. p. 308-319. 